\title{
Impulsive Traits and 5-HT2A Receptor Promoter Polymorphism in Alcohol Dependents: Possible Association but No Influence of Personality Disorders
}

\author{
U.W. Preuss G. Koller B. Bondy M. Bahlmann M. Soyka
}

Department of Psychiatry, Ludwig-Maximilians Universität München, Germany

\section{Key Words}

5-HT2A receptor promoter polymorphism - Impulsive behavior - Alcohol dependents - Antisocial personality disorder $\cdot$ Borderline personality disorder

\begin{abstract}
Objective: Impulsive behavior in alcoholics puts them at serious risk of severer course of disease and has been related to the serotonergic neurotransmission dysfunction. The aim of this study is to investigate the association between impulsive aggression in alcohol dependents with regard to the $\mathrm{G}-1438 \mathrm{~A}$ polymorphism in the promoter region of the $5-\mathrm{HT} 2 \mathrm{~A}$ receptor gene. Furthermore, we investigated the statistical interaction between 5-HT2A alleles, antisocial personality disorder (APD) and impulsive aggression in alcohol dependents. Alcohol dependents were investigated because these personality disorders and impulsive behavior are very frequent in alcohol dependence anf of clinical relevance. Methods: One hundred and thirty-five patients of German descent meeting DSM-IV criteria of alcohol dependence were recruited. Blood samples were taken from alcohol dependents to determine 5-HT2A promoter polymorphisms using PCR (polymerase chain reaction) of lymphocyte DNA. Impulsive aggression was assessed using
\end{abstract}

a German version of the Barratt Impulsiveness Scale which was translated and backtranslated. Alcohol dependents were subdivided into low- or high-impulsivity groups using a median split of the Barratt score. APD and borderline personality disorder (BPD) were assessed using the SCID-II interview. Results: The low-impulsivity group was slightly older and showed a later age at alcoholism onset than the highly impulsive group. Alcohol dependents with high impulsive traits showed a significant association with 5-HT2A 1438 A alleles. After excluding alcohol dependents with APD or BPD from the analysis, this association remained significant. Furthermore, no association between APD, BPD and 5-HT2A alleles was noted. Conclusions: Inpatient alcohol dependents showed a significant association between 5-HT2A $A$ alleles and impulsive traits, independent of the presence of APD or BPD. No association was noted between personality disorders and the polymorphism. This is the first report about an association of 5-HT2A promoter polymorphism and impulsive behavior in alcohol dependents. This finding may refer only to impulsive traits and may be independent of personality disorders in this sample. These results have to be confirmed in larger samples and in healthy control subjects to determine whether this association is of general validity.

Copyright $\odot 2001$ S. Karger AG, Base

\begin{tabular}{ll}
\hline KARGER & ( ) 2001 S. Karger AG, Basel \\
Fax +4161306 1234 & \\
$\begin{array}{l}\text { E-Mail karger@karger.ch } \\
\text { www.karger.com }\end{array}$ & $\begin{array}{l}\text { Accessible online at: } \\
\text { www.karger.com/journals/nps }\end{array}$
\end{tabular}

Ulrich W. Preuss, MD

Psychiatrische Klinik und Poliklinik, Ludwig-Maximilians-Universität München Nussbaumstrasse 7

D-80336 München (Germany)

Tel. +49 895160 5740, Fax +49895160 5748, E-Mail up@psy.med.uni-muenchen.de 


\section{Introduction}

The term impulsivity is usually reserved for maladaptive behavior. The behavioral pattern thought to reflect impulsivity encompasses actions that appear poorly conceived, prematurely expressed, unduly risky or inappropriate to the situation and often results in undesirable consequences. When such actions have positive outcomes, they tend not to be seen as signs of impulsivity, but as indicators of boldness, quickness, spontaneity, courage or unconventionality [1]. Impulsivity has been subdivided into several entities. However, it is not clear whether these entities share a common or different neurobiological or genetic background [2]. Even if impulsive behavior is often related to psychiatric or neurological disorders, these entities of impulsive behavior also play a role in many daily situations like those encountered in car-driving or professional occupations such as aircraft pilots. It can even have positive aspects, leading to social and career success [2].

However, looking at impulsive behavior in psychiatric diseases, it is one of the key characteristics in a number of psychiatric disorders, particularly personality dosorders. Both borderline (BPD) and antisocial personality disorder (APD) are strongly associated with impulsive behavior and are suggested to show low CNS serotonergic activity [3-5]. Furthermore, personality disorders such as BPD or APD have been identified as high risk factors for violent acts [6].

The diagnostic criteria for APD and BPD according to DSM-IV include impulsivity-related items. In APD these are: failure to plan ahead, irritability and aggression, as indicated by repeated physical fights or assaults, reckless disregard for safety of self or others and consistent irresponsibility as indicated by repeated failure to sustain consistent work behavior or honor financial obligations. In BPD they are: impulsivity in at least two areas that are potentially self-damaging, affective instability due to a marked reactivity of mood and inappropriate, intense anger or difficulty in controlling anger. Whereas BPD occur more often in females than in males [7], APD is much more frequent in males than in females [8].

Increased impulsivity has been suggested as an important risk factor for both the development of alcohol dependence and its prognosis [9]. It may lead to thoughtless sampling of alcohol at an age or under circumstances where a person with greater self-control would abstain or control the amount of drinking and may also lead to entry into social circles where excessive use of alcohol or drugtaking are considered normal behavior, and finally, im- pulsive behavior may result in a high rate of dropout from treatment [2]. Thus, in analyzing the relationship between impulsive behavior and allele frequencies of candidate gene polymorphisms, the alcohol dependence characteristics might serve as possible confounders of impulsivity since they are related to impulsive behavior.

In a number of studies, increased impulsivity and related traits such as irritability and aggression have been related to a low brain serotonin (5-HT) turnover, e.g. as indicated by reductions in neurochemical and neuropharmacological indices of central 5-HT activity (e.g. low cerebrospinal fluid 5-hydroxyindoleacetic acid) [10-12].

Impulsive aggressive traits were inversely correlated with the number of binding sites $\left(\mathrm{B}_{\max }\right)$ in platelet $\left[{ }^{3} \mathrm{H}\right]$ paroxetine binding studies of 24 subjects with personality disorder compared to 12 controls [4]. It was concluded that a reduced number of platelet 5-HT transporter sites may correlate with impulsive and aggressive behavior in patients with personality disorder. However, our recent results $[13,14]$ did not show any relationship between $\left[{ }^{3} \mathrm{H}\right]$ paroxetine binding sites and intensity of impulsive and aggressive traits in alcohol dependents.

The A-1438G promoter polymorphism of the 5-HT2A gene [15] has been associated with anorexia nervosa [15, 16], obsessive-compulsive disorder [16] and seasonal affective disorder [17]. However, negative associations of this polymorphism with schizophrenia [18] and anorexia nervosa [19] have also been reported.

Functional analysis of this promoter polymorphism showed differences neither in basal activity nor when promoter activity was induced by cAMP and protein-kinaseC-dependent mechanisms [20]. Thus, this polymorphism might serve as marker of functional relevant genetic sites within or near the 5-HT2A gene on chromosome 13 (13q14-q21). However, despite extensive screening, no frequent functional variant was detected in the coding region of the 5-HT2A gene itself [21]. Furthermore, this promoter polymorphism is in nearly complete linkage disequilibrium with the silent 5-HT2A T102C variant, which has been investigated in various diseases $[13,14]$.

Thus possible functional consequences on the 5-HT system and association with impulsive behavior have yet to be established.

The aim of this study was to investigate the association between 5-HT2A promoter alleles and impulsive traits in a sample of hospitalized alcohol dependents. Impulsive traits are an important criteria of APD and BPD behavior. Thus, we also investigate the interaction between these disorders with impulsive behavior and the 5-HT2A promoter alleles. As an additional hypothesis, we tested 
Table 1. Sample characteristics

\begin{tabular}{|c|c|c|c|c|c|}
\hline & \multirow{2}{*}{$\begin{array}{l}\text { Alcohol } \\
\text { dependents }\end{array}$} & \multirow{2}{*}{$\begin{array}{l}\text { Low-impulsivity } \\
\text { group }\end{array}$} & \multirow{2}{*}{$\begin{array}{l}\text { High-impulsivity } \\
\text { group }\end{array}$} & \multicolumn{2}{|l|}{$\mathrm{t}$ test } \\
\hline & & & & $\mathrm{t}$ value & $\mathrm{p}$ \\
\hline Sex, M/F & $107 / 28$ & $40 / 11$ & $67 / 17$ & & \\
\hline Age, years & $41.8 \pm 8.8$ & $42.9 \pm 9.1$ & $41.2 \pm 8.6$ & 1.11 & 0.27 \\
\hline Age of onset, years & $29.7 \pm 9.6$ & $30.6 \pm 10.5$ & $29.1 \pm 9.1$ & 0.89 & 0.37 \\
\hline Dependence, years & $12.3 \pm 8.0$ & $13.7 \pm 9.7$ & $11.8 \pm 6.7$ & 1.32 & 0.19 \\
\hline Daily alcohol intake, g/day & $350.3 \pm 199.8$ & $322.1 \pm 169.8$ & $373.8 \pm 220.2$ & -1.26 & 0.20 \\
\hline
\end{tabular}

whether the association between impulsive behavior and the 5-HT2A promoter alleles shows a statistical interaction with gender due to the suggested differences in impulsive behavior in dependents [22].

\section{Materials and Methods}

\section{Patients}

One hundred and thirty-five patients (107 males, 28 females; table 1) were recruited consecutively from an addiction ward for treatment of alcohol dependence. All patients were older than 18 years and met ICD-10 and DSM-IV criteria of alcohol dependence assessed with a structured interview (SCID: Structured Clinical Interview according to DSM-IV, German version [23], SSAGA (Semi-Structured Interview for Assessment of Genetics in Alcoholism, [24] and a comprehensive psychiatric examination by one of the authors (U.W.P. or M.S.) Patients with other axis I disorders were excluded.

All patients were investigated 2 weeks after admission and after alcohol withdrawal free of any psychopharmacological treatment (detailed characteristics are given in table 1). Age of onset of alcohol dependence was assessed computing the mean of retrospectively obtained first alcohol dependence ages by onset criteria as mentioned in DSM-IV by the SSAGA: Higher consumption of alcohol than intended, attempts to stop or control alcohol consumption, significant time spent comsuming alcohol or recovering from alcohol intake, regular withdrawal symptoms during important daily obligations like school or work, reduction of important occupational or private activities because of alcohol intake, continued alcohol consumption despite the occurrence of psychological or physical harm and occurrence of $50 \%$ higher tolerance to alcohol effects. Daily alcohol intake was obtained using the typical daily average alcohol consumption of 1 week during the last 30 days before admission. Pure alcohol intake was computed in grams/day. Duration of alcohol dependence was computed as the difference between age and age of onset. Impulsivity in alcohol dependents was assessed using the German version of the Barratt Impulsiveness Scale [25]. A total score was computed. To distinguish between a low- and high-impulsivity subgroup, a median split of the total score was performed.

Personality disorders were assessed using the SCID-II questionnaire (axis II diagnoses) according to DSM-IV diagnostic criteria [23]. The diagnosis of an APD was made if the minimum of DSM-IV conduct disorder (antisocial traits under the age of 15) and adult antisocial disorder (antisocial traits above the age of 18) was met. The diagnosis of BPD was made if the patients met the minimum of
DSM-IV criteria. The frequency of each personality disorder was counted and additionally proved with a thorough psychiatric and clinical assessment by 2 independent psychiatrists (U.W.P. and M.S.)

\section{Genotyping}

Genomic DNA was extracted from blood samples and genotyped for 5-HT2A promoter polymorphism. A 468-basepair region was amplified using the primers already described [15] under standard procedures. The reaction mixture contained $50 \mathrm{ng} / \mu \mathrm{l}$ of DNA, $0.6 \mu M$ of each primer, $200 \mu M \mathrm{dNTP}$ and $1.25 \mathrm{U}$ AmpliTaq Gold with the appropriate buffer (Perkin Elmer). Samples were amplified for 30 cycles, annealing temperature was $60^{\circ} \mathrm{C}$. The 468 -basepair product was digested with $10 \mathrm{MspI}$ for $14 \mathrm{~h}$, yielding two fragments of 244 and 224 basepairs in size, further separated on a $2.5 \%$ agarose gel and visualised with ethidium bromide $(1 \mu \mathrm{l} / 5 \mathrm{ml})$.

\section{Statistics}

Statistics were performed using SPSS Software (Statistical Package for Social Sciences, Ver. 9.0., 1997; SPSS Inc., Chicago, Ill., USA). All continuous data were tested for normal distribution.

Beside descriptive statistics, the relationships between Barrat impulsivity scores, characteristics of alcohol dependence and 5HT2A G/A-genotype were computed using one-way ANOVA. To compute the differences between low- and high-impulsivity subgroups, the Student $t$ test for independent samples was used. To prove the associations between personality disorders, 5-HT2A genotypes and impulsive behavior, a two-way ANOVA was used. Impulsive behavior was entered into the ANOVA as the dependent variable. Analyzing the interaction between impulsivity and the diagnosis of BPD or APD and gender, the impulsivity score was entered as the dependent, and personality disorders, gender and 5-HT2A genotypes as the independent factors. A two-tailed $\alpha$-significance level of $\mathrm{p}<0.05$ was defined to be statistically significant.

\section{Sample Size Estimation}

Based on the article by Manuck et al. [26] who compared 251 healthy men and women according to their impulsive traits with respect to tryptophan hydroxylase (TPH) genotype, a sample size estimation was made. The TPH intron 7 polymorphism (alleles U and $\mathrm{L}$ ) showed a similar allele population frequency as compared to the allele frequencies of the 5-HT2A A-1438G promoter polymorphism (L: 61\%, U: 39\% [26]; A: 39\%; G: 61\% [18]).

Based on a power of $0.9(1-\beta)$, an $\alpha$ level of 0.05 and on the means of the Barratt Impulsiveness Scale with respect to TPH U and L phenotype according to Manuck et al. [26], the sample size estimation resulted in 70 persons per group ( $\mathrm{n}=140$ for the whole sample). 
Table 2. Association results, influence of personality disorders, alcohol dependence characteristics and 5-HT2A genotypes

\begin{tabular}{|c|c|c|c|c|c|}
\hline & \multicolumn{3}{|c|}{ 5-HT2A genotype } & \multicolumn{2}{|c|}{ ANOVA } \\
\hline & AA & AG & GG & F value & $\mathrm{p}$ \\
\hline Sex, M/F $(n=135)$ & $24 / 5(22 \%)$ & $56 / 16(46 \%)$ & $27 / 7(32 \%)$ & & \\
\hline BIS score all patients & $30.8 \pm 2.7$ & $30.7 \pm 2.6$ & $32.1 \pm 2.4$ & 3.76 & 0.02 \\
\hline BIS score without APD patients & $30.2 \pm 2.6$ & $30.7 \pm 2.6$ & $32.1 \pm 2.4$ & 4.22 & 0.01 \\
\hline BIS score without BPD patients & $30.8 \pm 2.6$ & $30.6 \pm 2.5$ & $32.0 \pm 2.6$ & 3.22 & 0.04 \\
\hline \multicolumn{6}{|c|}{ Interaction with alcohol dependence characteristics $(n=135)$} \\
\hline Age at onset, years & $30.0 \pm 12.4$ & $29.4 \pm 9.5$ & $29.1 \pm 7.5$ & 0.80 & 0.93 \\
\hline Duration of alcohol dependence, years & $11.9 \pm 6.9$ & $12.9 \pm 8.6$ & $11.7 \pm 7.6$ & 0.63 & 0.53 \\
\hline Daily alcohol intake, g/day & $345.3 \pm 188.9$ & $362.2 \pm 220.6$ & $316.5 \pm 162.1$ & 0.34 & 0.71 \\
\hline
\end{tabular}

BIS = Barratt Impulsiveness Scale

\section{Etical Standards}

Informed consent was obtained from patients and controls after complete and extensive description of the study. The study was approved by the ethical committee of the Ludwig-Maximilians University of Munich. All patients signed a written informed consent.

\section{Results}

One hundred and thirty-five alcohol dependents (107 males and 28 females, mean age $41.8 \pm 8.8$ years; table 1 ) meeting criteria for DSM-IV alcohol dependence were recruited. All patients were Caucasian and of German descent.

APD according to DSM-IV was present in 25 patients $(16.6 \%)$, BPD in 23 patients (15.3\%).

\section{Genotype Results}

Genotyping the DNA in our sample, we observed a frequency for the A allele of $48 \%$ and of $52 \%$ for the $\mathrm{G}$ allele (table 2). Homozygosity for the AA genotype was found in $22 \%(\mathrm{n}=29)$ of alcohol dependents, $46 \%$ had the $\mathrm{AG}$ genotype $(\mathrm{n}=72)$ and $32 \%(\mathrm{n}=34)$ were homozygous for the GG genotype (table 2). Our data followed the HardyWeinberg equilibrium $(2=0.435$, d.f. $=2, p=0.804)$ and corresponded to data observed in Japanese alcohol dependents (AA: 23\%; AG: 52\%; GG: 25\% [27]). Clinical parameters such as age of onset, mean duration of alcohol dependence (12.4 \pm 7.9 years) or mean alcohol intake (346.8 $\pm 200.1 \mathrm{~g} /$ day) showed no significant association with allelic distributions (table 2). However, the group of highly impulsive patients was significantly younger and tended to have a lower age of onset, longer duration of alcohol dependence and higher daily alcohol intake (table 1).

Impulsive Traits and 5-HT2A Receptor

Promoter Polymorphism in Alcohol

Dependents

\section{Impulsive Traits and 5-HT2A Alleles}

Comparing the Barrett Impulsiveness Scale total scores between 5-HT2A genotypes, significantly lower scores were found for AA genotype carriers (table 2). This association remained significant even after excluding patients with APD and BPD.

To test for spurious associations, an additional analysis was made comparing homozygous AA and GG genotype carriers. The association remained significant $(\mathrm{t}$ value $=$ -2.04 , d.f. $=61 ; p=0.04)$.

\section{Impulsive Traits, $A P D$ and $B P D$}

No statistical interaction was found for APD, BPD and 5-HT2A genotypes. Furthermore, APD and BPD were not associated with impulsive behavior (table 3).

\section{Impulsive Traits, 5-HT2A Alleles and Gender}

No statistical interaction was found between gender and 5-HT2A genotypes (table 3).

\section{Discussion}

In our study, the association between impulsive behavior and genotypes was significant at $\mathrm{p}=0.02$, above the usual $\mathrm{p}<0.05 \alpha$-significance level. Furthermore, we proved the influence of personality disorders which may be major confounders in studies about impulsive behavior. We did not compare alcohol dependents with a control sample but looked for the association between 5HT2A promoter alleles and impulsive behavior among alcohol dependents.

To ensure sufficient power for this association study, a power analysis was carried out before starting the study

Neuropsychobiology 2001;43:186-191 
Table 3. Statistical interaction between APD, BPD, gender and 5-HT2A genotypes

\begin{tabular}{|c|c|c|c|c|c|}
\hline & \multicolumn{3}{|c|}{ 5-HT2A genotype } & \multicolumn{2}{|c|}{ ANOVA } \\
\hline & $\mathrm{AA}$ & AG & GG & F value & $\mathrm{p}$ \\
\hline \multicolumn{6}{|c|}{ APD $\times 5$-HT2A genotype } \\
\hline APD positive & $32.5 \pm 2.5$ & $30.6 \pm 3.2$ & $32.3 \pm 2.9$ & \multirow{2}{*}{0.468} & \multirow{2}{*}{0.68} \\
\hline APD negative & $30.2 \pm 2.6$ & $30.7 \pm 2.6$ & $32.1 \pm 2.4$ & & \\
\hline \multicolumn{6}{|c|}{$\mathrm{BPD} \times 5$-HT2A genotype } \\
\hline BPD positive & $30.8 \pm 2.6$ & $30.6 \pm 2.5$ & $32.0 \pm 2.6$ & \multirow[b]{2}{*}{0.741} & \multirow{2}{*}{0.69} \\
\hline BPD negative & $30.3 \pm 4.0$ & $31.1 \pm 3.7$ & $32.7 \pm 1.9$ & & \\
\hline \multicolumn{6}{|c|}{ Gender $\times 5$-HT2A genotype } \\
\hline Male & $31.0 \pm 2.8$ & $30.8 \pm 2.7$ & $32.0 \pm 2.5$ & \multirow{2}{*}{0.634} & \multirow[b]{2}{*}{0.53} \\
\hline Female & $30.0 \pm 2.7$ & $30.3 \pm 2.6$ & $32.7 \pm 2.1$ & & \\
\hline
\end{tabular}

based on a similarly designed study by Manuck et al. [26]. The sample size estimation resulted in a whole sample size of 140 patients; 135 patients were included into our study.

To confirm our results, we compared the impulsive traits of homozygous genotype carriers (AA and GG). The association between $\mathrm{A}$ alleles and impulsive behavior remained significant and reduced the liability for spurious associations.

Regarding the possible consequences of impulsive behavior on the course of alcohol dependence and vice versa, we proved the relationship between alcohol dependence characteristics and impulsive behavior to test its role as a possible confounder. We found no evidence that impulsive behavior assessed by the Barrett Impulsiveness Scale, had any impact on alcohol intake, duration of alcohol dependence or age of onset.

However, age of onset of alcoholism is not at all related to heredity, as shown by twin studies [28].

Additionally, our data were obtained retrospectively from inpatient alcoholics after alcohol withdrawal. Thus, prospective studies are needed to confirm the influence of impulsive behavior on the prognosis of alcohol dependence. Furthermore, the impulsive traits assessed by the Barrett Impulsiveness Scale may be part of every person in comparison to impulsive aggressive traits which may be found more in persons with antisocial or borderline personality behavior as mentioned in the DSM-IV criteria. This may explain why we found no influence of personality disorder on this trait.

In this study, alcohol dependents being homozygous for allele A of the promoter polymorphism in the 5-HT2A gene scored significantly lower on measures of impulsive behavior. This is the first report showing an association between 5-HT2A polymorphisms and impulsive behav- ior. Polymorphisms of other parts of the 5-HT system have already been related to impulsive behavior.

TPH polymorphisms, for which a biallelic intronic polymorphism (U and L) has been reported [29], were associated with psychometric indices of impulsive aggression in one published study of 40 patients with mixed personality disorder [5]. Although no association was observed in women, men homozygous for the TPH L allele showed higher score of aggression and irritability than subjects having the pooled UL and UU genotypes. However, due to sample restrictions to personality disorder patients, the small number of men studied $(n=21)$ and the presence of only $2 \mathrm{UU}$ homozygous males warrant cautious interpretations. Compared to that, our results showed no influence of gender on impulsive behavior or 5-HT2A genotypes.

In one of the two prior studies relating TPH alleles with impulsive, aggressive or anger-related traits, New et al. [5] reported that assault and irritability scores on the BDHI were higher in LL homozygous subjects than in subjects with the UU and UL genotypes among 21 men with various personality disorders. We could not replicate these findings, even if our results are contradictory to those of New et al. [5].

To the extent that genetic factors account for some portion of interindividual variability in impulsive-related traits, and may do so through variations in CNS serotonergic transmission, it follows that heritable influences might be expressed through differences in genes regulating 5-HT synthesis, release, reuptake and metabolism of receptor activation.

Polymorphisms have been identified in several genes that code for elements of the 5-HT system, including $\mathrm{TPH}$, the 5-HT transporter, monoamine oxidase and several of the 5-HT receptors [30]. According to the methodi-

$\overline{190} \quad \overline{\text { Neuropsychobiology 2001;43:186-191 }}$ 
cal limitations of the results of Spurlock et al. [20], the functional consequences of the 5-HT2A promoter A$1438 \mathrm{G}$ polymorphism e.g. on expression of mRNA or receptor density or function have yet to be established. We found the AA genotype of the 5-HT2A A-1438G polymorphism to be related to lower impulsive behavior. There is a preponderance of literature suggesting that impulsive behavior is related to low serotonergic transmission. Thus, it can be speculated that this polymorphism associated with changes in impulsive behavior may result in an altered receptor sensitivity of the 5-HT2A receptor. However, no reports from the literature are available to prove this relationship or the influence of this polymorphism on serotonergic transmission. In conclusion, certain 5-HT2A promoter polymorphism may contribute to impulsive behavior in alcohol dependents independent of APD or BPD.

General conclusions about the specificity of our findings should be drawn with care. A second independent study is needed to confirm these results.

\section{References}

1 Daruna JH, Barness PA: A neurodevelopmental view of impulsivity; in McCown WG, Johnson JS, Shure MB (eds): The Impulsive Client: Theory, Research and Treatment. Washington, American Psychological Association, 1993, pp 132-138.

2 Evenden J: Impulsivity: A discussion of clinical and experimental findings. J Psychopharmacol 1999;13:180-192.

3 Coccaro EF, Siever LJ, Klar HM, Maurer G, Cochrane K, Cooper TB, Mohs RC, Davis KL: Serotonergic studies in patients with affective and personality disorders: Correlates with suicidal and impulsive aggressive behavior. Arch Gen Psychiatry 1989;46:587-599.

4 Coccaro EF, Kavoussi RJ, Sheline YI, Lish JD, Csernansky JG: Impulsive aggression in personality disorder correlates with tritiated paroxetine binding in the platelet. Arch Gen psychiatry 1996:53:531-536.

5 New AS, Gelernter J, Yovell Y, Trestman RL, Nielsen DA, Silverman J, Mitropoulou V, Siever LJ: Tryptophan hydroxylase genotype is associated with impulsive-aggression measures: A preliminary study. Am J Med Genet 1998;81:13-17.

6 Else LT, Wonderlich SA, Beatty WW, Christie DW, Staton RD: Personality characteristics of men who physically abuse women. Hosp Commun Psychiatry 1993;44:54-58.

7 Grilo CM, Becker DF, Fehon DC, Walker ML, Edell WS, McGlashan TH: Gender differences in personality disorders in psychiatrically hospitalized adolescents. Am J Psychiatry 1996; 153:1089-1091.

8 Carter JD, Joyce PR, Mulder RT, Sullivan PF, Luty SE: Gender differences in the frequency of personality disorders in depressed outpatients. J Person Disord 1999;13:67-74.

9 Nagoshi CT, Wilson JR, Rodriguez LA: Impulsivity, sensation seeking and behavioral and emotional responses to alcohol. Alcohol Clin Exp Res 1991;15:661-667.

10 Coccaro EF, Harvey PD, Kupsaw-Lawrence E, Herbert JL, Bernstein DP: Development of neuropharmacologically based behavioral assessments of impulsive aggressive behavior. J Neuropsych Clin Neurosci 1991;3:44-51.

11 Virkkunen M, Goldman D, Nielsen DA, Linnoila M: Low brain serotonin turnover rate (low CSF 5-HIAA) and impulsive violence. J Psychiatr Neurosci 1995;20:271-275.

12 Virkkunen M, Rawlings R, Tokola R, Poland RE, Guidotti A, Nemeroff C, Bissette G, Kalogeras K, Karonen SL, Linnoila M: CSF biochemistries, glucose metabolism, and diurnal activity rhythms in alcoholic, violent offenders, fire setters, and healthy volunteers. Arch Gen Psychaitry 1994;51:20-27.

13 Preuss UW, Koller G, Bahlmann M, Soyka M, Bondy B: No association between suicidal behavior and 5-HT2A T102C polymorphism in alcohol dependents. Am $\mathrm{J}$ Med Genet, in press.

14 Preuss UW, Soyka M, Bahlmann M, Wenzel K, Behrens S, de Jonge S, Krüger M, Bondy B: Serotonin transporter gene regulatory region polymorphism (5-HTTLPR), [3H]-paroxetine binding in healthy controls and alcohol dependents and its relation to impulsivity. Psychiatry Res, in press

15 Collier DA, Arranz MJ, Li T, Mupita D, Brown $\mathrm{N}$, Treasure J: Association between 5-HT2A gene promoter polymorphism and anorexia nervosa Lancet 1997;350:412.

16 Enoch MA, Kaye WH, Rotondo A, Greenberg BD, Murphy DL, Goldman D: 5-HT2A promoter polymorphism -1438G/A, anorexia nervosa, and obsessive-compulsive disorder. Lancet 1998;351:1785-1786.

17 Enoch MA, Goldman D, Barnett R, Sher L, Mazzanti CM, Rosenthal NE: Association between seasonal affective disorder and the 5HT2A promoter polymorphism, -1438G/A. Mol Psychiatry 1999;4:89-92.

18 Ohara K, Nagai M, Tani K, Tsukamoto T, Ohara K: Schizophrenia and the serotonin-2A receptor promoter polymorphism. Psychiatry Res 1999;85:221-224.

19 Ziegler A, Hebebrand J, Gorg T, Rosenkranz K, Fichter M, Herpertz Dahlmann B, Remschmidt H, Hinney A: Further lack of association between the 5-HT2A gene promoter polymorphism and susceptibility to eating disorders and a meta-analysis pertaining to anorexia nervosa. Mol Psychiatry 1999;4:410-412.

20 Spurlock G, Heils A, Holmans P, Williams J, D’Souza UM, Cardno A, Murphy KC, Jones L, Buckland PR, McGuffin P, Lesch KP, Owen MJ: A family based association study of T102C polymorphism in 5HT2A and schizophrenia plus identification of new polymorphisms in the promoter. Mol Psychiatry 1998;3:42-49.

21 Erdmann J, Shimron-Abarbanell D, Rietschel M, Albus M, Maier W, Korner J, Bondy B, Chen K, Shih JC, Knapp M, Propping P, Nothen MM: Systematic screening for mutations in the human serotonin-2A (5-HT2A) receptor gene: Identification of two naturally occurring receptor variants and association analysis in schizophrenia. Hum Genet 1996;97:614-619.

22 Waldeck TL, Miller LS: Gender and impulsivity differences in licit substance use. J Subst Abuse 1997;9:269-275.

23 Wittchen HU, Zaudig M, Fydrich T: SKID-I/ II: Strukturiertes klinisches Interview für DSM-IV. Goettingen, Hogrefe, 1996.

24 Bucholz KK, Cadoret R, Cloninger CR, Dinwiddie $\mathrm{SH}$, Hesselbrock VM, Nurnberger JI, Reich T, Schmidt I, Schuckit MA: A new, semistructured psychiatric interview for use in genetic linkage studies: A report on the reliability of the SSAGA. J Stud Alcohol 1995;55:149158.

25 Barratt ES: Factor analysis of some psychometric measures of impulsiveness and anxiety. Psychol Rep 1965;16:547-554.

26 Manuck SB, Flory JD, Ferrell RE, Dent KM, Mann JJ, Muldoon MF: Aggression and angerrelated traits associated with a polymorphism of the tryptophan hydroxylase gene. Biol Psychiatry 1999;45:603-614.

27 Nakamura T, Matsushita S, Nishiguchi N, Kimura M, Yoshino A, Higuchi S: Association of a polymorphism of the 5HT2A receptor gene promoter region with alcohol dependence. Mol Psychiatry 1999;4:85-88.

28 Rose RJ, Kaprio J, Winter T, Koskenvuo M, Viken RJ: Familial and siocioregional environmental effects on abstinence from alcohol at age sixteen. J Stud Alcohol Suppl 1999;13:6374.

29 Nielsen DA, Dean M, Goldman D: Genetic mapping of the human tryptophan hydroxylase gene on chromosome 11 , using an intronic conformational polymorphism. Am J Hum Genet 1992;51:1366-1371.

30 Goldman D, Lappalainen J, Ozaki N: Direct analysis of candidate genes in impulsive behaviours. Ciba Found Symp 1996;194:139-152. 